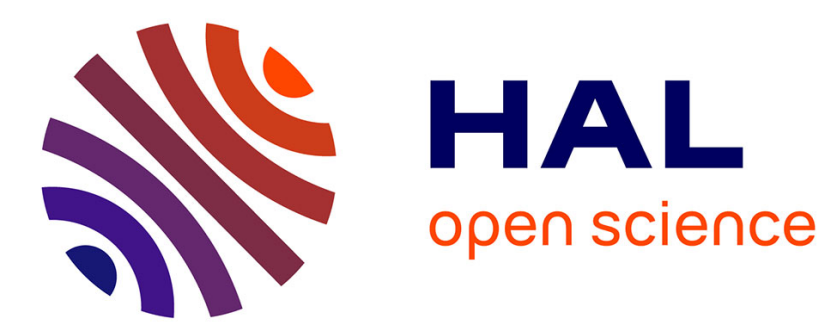

\title{
BioRoot RCS Extracts Modulate the Early Mechanisms of Periodontal Inflammation and Regeneration
}

Charlotte Jeanneau, Thomas Giraud, Patrick Laurent, Imad About

\section{To cite this version:}

Charlotte Jeanneau, Thomas Giraud, Patrick Laurent, Imad About. BioRoot RCS Extracts Modulate the Early Mechanisms of Periodontal Inflammation and Regeneration. Journal of Endodontics, 2019, 45 (8), pp.1016-1023. 10.1016/j.joen.2019.04.003 . hal-03547421

\section{HAL Id: hal-03547421 \\ https://hal.science/hal-03547421}

Submitted on 28 Jan 2022

HAL is a multi-disciplinary open access archive for the deposit and dissemination of scientific research documents, whether they are published or not. The documents may come from teaching and research institutions in France or abroad, or from public or private research centers.
L'archive ouverte pluridisciplinaire HAL, est destinée au dépôt et à la diffusion de documents scientifiques de niveau recherche, publiés ou non, émanant des établissements d'enseignement et de recherche français ou étrangers, des laboratoires publics ou privés. 
Charlotte Jeanneau, PhD, *

Thomas Giraud, $P h D,{ }^{* \dagger}$

Patrick Laurent, $P h D,{ }^{*+}$ and

Imad About, PhD, *
BioRoot RCS Extracts

Modulate the Early

Mechanisms of Periodontal

Inflammation and Regeneration

\section{SIGNIFICANCE}

Root canal sealer inflammatory and regeneration potentials can be predicted using in vitro models. Within the limitations of this work performed in vitro, BioRoot RCS has antiinflammatory and regenerative potentials.

\section{ABSTRACT}

Introduction: The balance between periapical tissue inflammation and regeneration after the removal of necrotic/infected tissues is pivotal in determining the success of endodontic treatment. This study was designed to investigate the effect of silicate-based root canal sealer BioRoot RCS (BRCS; Septodont, Saint-Maur-des-Fossés, France) on modulating the inflammatory mechanisms and early steps of regeneration initiated by human periodontal ligament (PDL) fibroblasts. Methods: Samples of BRCS and Pulp Canal Sealer (PCS; SybronEndo, Orange, CA) were incubated in culture medium to obtain material extracts. To simulate bacterial infection and endodontic sealer use, PDL fibroblasts were stimulated with lipopolysaccharides and cultured with material extracts. The secretion of proinflammatory cytokine (interleukin 6) and growth factor (transforming growth factor beta 1) were quantified by enzyme-linked immunosorbent assay. Inflammatory cell recruitment sequence was investigated using a human inflammatory monocytic cell line (THP-1) that can be activated into macrophage-like cells. The adhesion of THP-1 to endothelial cells (human umbilical vein endothelial cells) was studied using fluorescent THP-1, their migration using Boyden chambers, and their activation into macrophage-like cells using a cell adhesion assay. The proliferation of PDL fibroblasts was quantified by the 3-(4,5-dimethylthiazol-2-yl)-2,5diphenyltetrazolium bromide assay, whereas the migration of PDL stem cells was investigated using Boyden chambers after immunofluorescence and reverse transcription polymerase chain reaction characterization. Results: Interleukin 6 secretion decreased with BRCS, whereas it increased with PCS. Transforming growth factor beta 1 secretion significantly increased only with BRCS. The material extracts did not affect THP-1 adhesion to human umbilical vein endothelial cells, but only BRCS inhibited their migration. Moreover, activation of THP-1 decreased with BRCS and to a lesser extent with PCS. Finally, BRCS increased PDL fibroblast proliferation without affecting PDL stem cell migration. By contrast, PCS decreased PDL fibroblast proliferation and PDL stem cell migration. Conclusions: This work shows that the endodontic sealers modulate the PDL inflammatory and regeneration potentials in vitro. It demonstrates that BRCS has anti-inflammatory effects and the potential to promote tissue regeneration. (J Endod 2019;45:1016-1023.)

\section{KEY WORDS}

Endodontic sealer; inflammation; periodontal ligament; regeneration; tricalcium silicates
Endodontic treatments are required to heal or prevent apical periodontitis, which may appear as a result of bacterial infection of the root canal space. Adequate root shaping, cleaning, and filling are prerequisites of endodontic treatment. Physicochemical shaping and disinfection are of prime importance because of the complex root canal anatomy and microbial biofilm. These procedures aim at removing necrotic tissues and disorganizing the biofilm. Completion of the filling procedure combines the use of guttapercha to a sealer to avoid endodontic reinfection. Although root canal sealers are applied into a cleaned root canal, these may exceed the apical foramina ${ }^{1}$ and be in contact with the inflamed periapical tissues. It is hypothesized that the subsequent sealer interaction with these periapical tissues may modulate the inflammatory response, its resolution, and the initiation of the lost tissue regeneration. 
The initial steps of inflammation include proinflammatory cytokine secretion and subsequent immune cell recruitment. The resolution of this inflammation is required to initiate the regenerative events initiated by growth factor secretion, cell proliferation, and stem cell migration to regenerate the lost tissues $^{2}$. In addition, it is well-known that these events can be modulated by dental materials ${ }^{3}$.

Root canal sealers have been developed for decades with the first being based on zinc eugenate followed by resinbased sealers, calcium hydroxide, or glass ionomers. Pulp Canal Sealer (PCS;

SybronEndo, Orange, CA) is one of the widely used zinc oxide-eugenol (ZOE) sealers which contains eugenol and has a potential cytotoxicity to periodontal cells ${ }^{4}$. Silicatebased materials are successfully used in canal perforation treatment, apexification, and pulp therapies, such as direct pulp capping, thanks to their biological and sealing properties ${ }^{5}$. For these reasons, silicate-based formulations with appropriate handling and viscosity have been also developed for root canal filling procedures. BioRoot RCS (BRCS; Septodont, Saint-Maur-des-Fossés, France) has been developed as a calcium silicate-based root canal sealer. It is composed of a powder that contains tricalcium silicates, zirconium oxide, and povidone, whereas the liquid contains polycarboxylate and calcium chloride. Recently conducted studies on BRCS have shown calcium release, alkalizing activity, apatite-forming ability ${ }^{6}$, and antimicrobial activity $^{7}$. Moreover, its biocompatibility has been shown on human periodontal ligament (PDL) cells ${ }^{8}$, PDL stem cells ${ }^{9}$, and pulp-derived mouse stem cells ${ }^{10}$. Indeed, after direct contact with pulp cells, BRCS induced a high level of mineralization, indicating the high potential of this material to induce regeneration ${ }^{11}$. Similarly, investigating the interaction of BRCS with PDL cells showed an increased secretion of angiogenic growth factors such as vascular endothelial growth factor and fibroblast growth factor 2 and the osteogenic bone morphogenetic protein $2^{12}$.

On the other hand, PDL cells secreted interleukin (IL)-6 and -8 and tumor necrosis factor alpha after stimulation with lipopolysaccharides (LPSs), indicating that these cells may play a role in initiating the inflammatory reaction ${ }^{13,14}$. Additionally, under similar conditions, they also expressed and secreted transforming growth factor beta 1 (TGF- $\beta 1$ ), which has been shown to play a significant role in mesenchymal stem cell recruitment ${ }^{15}$ and regulation of PDL osteoblastic differentiation ${ }^{16}$. However, investigations to evaluate the effect of the material on modulating PDL cell regeneration and inflammatory potential are still lacking. This study was designed to evaluate the effects of BRCS on the periapical tissue inflammatory response and the early steps of regeneration. To simulate bacterial infection of the root canal space and the filling procedure, PDL fibroblasts were stimulated with LPSs and cultured with sealers' extracts. PDL fibroblast secretion of IL-6 was quantified, and the involvement of these cells in the inflammatory cell recruitment sequence was evaluated using the human THP-1 inflammatory monocytic cell line by analyzing their adhesion to endothelial cells, their migration, and their activation at the injury site. Furthermore, the early regenerative events were studied by investigating TGF- $\beta 1$ secretion, fibroblast proliferation, and PDL stem cell migration.

\section{MATERIALS AND METHODS}

\section{Reagents}

Media, reagents, and cell culture supplies were from Dutscher (Brumath, France). Primary antibodies were provided by R\&D Systems (Lille, France) and secondary antibodies Alexa Fluor were provided by Life Technologies (Saint-Aubin, France).

\section{Human PDL Cell Culture and Characterization Primary PDL Cell Cultures}

PDL cells were obtained from immature third molars freshly extracted (males and females under 18 years old) in compliance with French legislation (informed patient consent and institutional review board approval of the protocol used) using the explant outgrowth method $^{17}$. Cells were cultured in minimum essential medium (MEM) supplemented with $10 \%$ fetal bovine serum, glutamine $2 \mathrm{mmol} / \mathrm{L}$, penicillin $100 \mathrm{UI} / \mathrm{mL}$, streptomycin $100 \mu \mathrm{m} / \mathrm{mL}$, and amphotericin B $0.25 \mu \mathrm{g} / \mathrm{mL}$ at $37^{\circ} \mathrm{C}$ and a $5 \% \mathrm{CO}_{2}$ atmosphere.

\section{Magnetic Stem Cell Sorting}

PDL STRO-1-positive cells were directly sorted from primary PDL cell cultures at passages 1 to 5 with mouse antihuman STRO-1 immunoglobulin $\mathrm{M}$ with immune magnetic beads according to the manufacturer's protocol (Dynal, Oslo, Norway) as described previously ${ }^{18}$. STRO-1-negative cells were characterized as fibroblasts as described previously ${ }^{3}$.

\section{Immunofluorescence PDL STRO-1- positive Cell Characterization}

PDL STRO-1-positive cells were cultured in 8-well glass culture chambers up to $70 \%$ confluence. Cells were washed with phosphate-buffered saline (PBS) with calcium and magnesium and fixed with $4 \%$ paraformaldehyde ( 15 minutes, $4^{\circ} \mathrm{C}$ ). Then, nonspecific binding sites were blocked with $1 \%$ bovine serum albumin ( 1 hour). Cells were incubated with primary antibodies (1 hour) against STRO-1 (5 $\mu \mathrm{g} / \mathrm{mL})$, CD90, CD105, CD44, CD106, CD166, CD19, and CD45 $(2.5 \mu \mathrm{g} / \mathrm{mL})$ or their respective isotypes. After washing, cells were incubated (45 minutes) with their respective secondary antibodies (ie, Alexa Fluor-488, $2 \mu \mathrm{g} / \mathrm{mL}$, and 4',6-diamidino-2-phenylindole [DAPI], $1 \mu \mathrm{g} / \mathrm{mL}$ ) for fluorescence microscopy.

\section{Reverse Transcription Polymerase Chain Reaction Characterization}

Total RNAs were isolated from PDL STRO-1positive cells using a PureLink RNA Mini Kit (Life Technologies). RNA samples (2 $\mu \mathrm{g}$ ) were reverse transcribed using a reverse transcription AMV system (Promega, Madison, WI). Polymerase chain reactions were performed to detect RNA expression of 4 stem cell transcription factors: KLF4, NANOG, OCT3/4, and SOX2. The reverse transcription polymerase chain reaction primer list is presented in Table 1.

\section{Material Extract Preparation}

Samples of BRCS and PCS were prepared according to the manufacturers' instructions

TABLE 1 - Reverse Transcription Polymerase Chain Reaction Primer Sequence

\begin{tabular}{lc} 
Primer & Sequence \\
OCT3/4-1 & 5'-CAGTGCCCGAAACCCACAC-3' \\
OCT3/4-2 & 5'-GGAGACCCAGCAGCCTCAAA-3' \\
KLF4-1 & 5'-GGGAGAAGACACTGCGTCAA-3' \\
KLF4-2 & 5'-TCCAGGTCCAGGAGATCGTT-3' \\
SOX2-1 & 5'-GTTGCCTGGCTTCTCTITG-3' \\
SOX2-2 & 5'-GCTGATTGGTCGCTAGAAAC-3' \\
NANOG-1 & 5'-AAGGTCCCGGTCAAGAAACAG-3' \\
NANOG-2 & 5'-CTTCTGCGTCACACCATTGC-3' \\
GAPDH-1 & 5'-GAAGGTGAAGTTCGGAGTC-3' \\
GAPDH-2 & 5'-GAAGATGGTGATGGGATTC-3' \\
\hline
\end{tabular}


and incubated in serum-free MEM (24 hours, $37^{\circ} \mathrm{C}$ ) to obtain unset material extracts. The resulting material extracts were filtered on $0.22-\mu \mathrm{m}$ filters. We tested a contact between the unset material and the culture media volume of $20 / 2 / 0.2 \mathrm{mg} / \mathrm{mL}$. The working dilution used in the next experiments was $0.2 \mathrm{mg} / \mathrm{mL}$. It was determined with the 3-(4,5-dimethylthiazol-2-yl)-2,5diphenyltetrazolium bromide (MTT) test as the quantity of sealer showing no toxic effects to PDL cells.

\section{Cytokine Secretion by PDL Fibroblasts \\ Cytokine Expression}

PDL fibroblasts were cultured in 8-well glass culture chambers up to $70 \%$ confluence. Cells were fixed and permeabilized with $70 \%$ ethanol (20 minutes, $4^{\circ} \mathrm{C}$ ). Then, nonspecific binding sites were blocked with $5 \%$ bovine serum albumin ( 1 hour). Cells were incubated with primary antibodies ( 1 hour) against IL-6 ( $1 \mu \mathrm{g} / \mathrm{mL})$, TGF- $\beta 1$ $(1 \mu \mathrm{g} / \mathrm{mL})$, or their isotypes. After washing, cells were incubated (45 minutes) with their respective secondary antibodies Alexa Fluor$488(1 \mu \mathrm{g} / \mathrm{mL})$ or Alexa Fluor-594 $(1 \mu \mathrm{g} / \mathrm{mL})$ and DAPI $(1 \mu \mathrm{g} / \mathrm{mL})$ for fluorescence microscopy.

\section{Cytokine Quantification}

PDL fibroblasts were cultured at confluence in 12-well plates. Cells were stimulated with LPS $(1 \mu \mathrm{g} / \mathrm{mL}, 4$ hours) and incubated with materia extract or serum-free MEM control media.

After 24 hours, the supernatants were used for IL- 6 and TGF- $\beta 1$ quantification by the enzymelinked immunosorbent assay using Duoset Kits (R\&D Systems, Minneapolis, MN) according to the manufacturer's instructions.

\section{Inflammatory Cell Recruitment Sequence}

Human Umbilical Vein Endothelial Cells and Inflammatory (THP-1) Cell Culture

Human umbilical vein endothelial cells (HUVECs; PromoCell, Heidelberg, Germany) were cultured in Endothelial Cell Growth
Medium 2 (PromoCell). THP-1 cells, a human monocytic inflammatory cell line that can be activated into macrophage-like cells (SigmaAldrich, St Louis, MO), were cultured in RPMI medium (supplemented with 10\% fetal bovine serum, $100 \mathrm{Ul} / \mathrm{mL}$ penicillin, $100 \mu \mathrm{g} / \mathrm{mL}$ streptomycin, $0.25 \mu \mathrm{g} / \mathrm{mL}$ amphotericin $\mathrm{B}$, $2 \mathrm{mmol} / \mathrm{L}$ L-glutamine, and $1 \mathrm{mmol} / \mathrm{L}$ sodium pyruvate) as described previously ${ }^{3}$.

\section{Conditioned Media Preparation}

PDL fibroblasts were cultured until they became confluent in 12-well plates and then were stimulated with LPS ( $1 \mu \mathrm{g} / \mathrm{mL}, 4$ hours). Next, they were incubated with material extract or serum-free MEM control media for 24 hours. The supernatants were then harvested and will be called conditioned media.

\section{Inflammatory THP-1 Cell Adhesion on HUVECs}

Confluent HUVECs $(80,000$ cells/cm²) were cultured in 12-well plates with the conditioned media ( 4 hours, $37^{\circ} \mathrm{C}$ ). THP-1 cells were first incubated with $0.1 \mu \mathrm{mol} / \mathrm{L}^{2}, 7^{\prime}$-bis-(2-
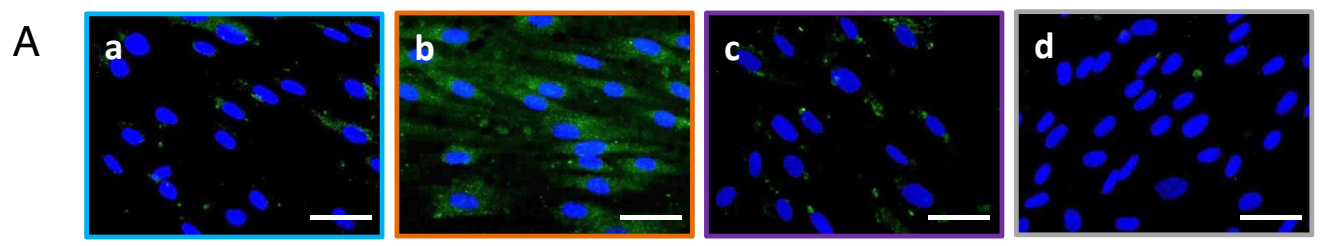

TGF- $\beta 1$
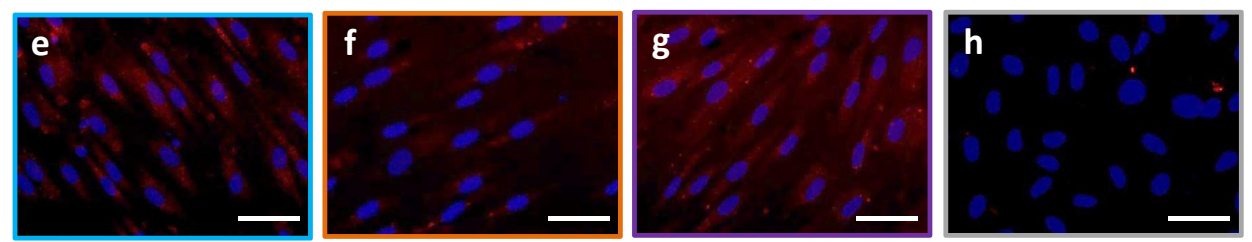

IL-6

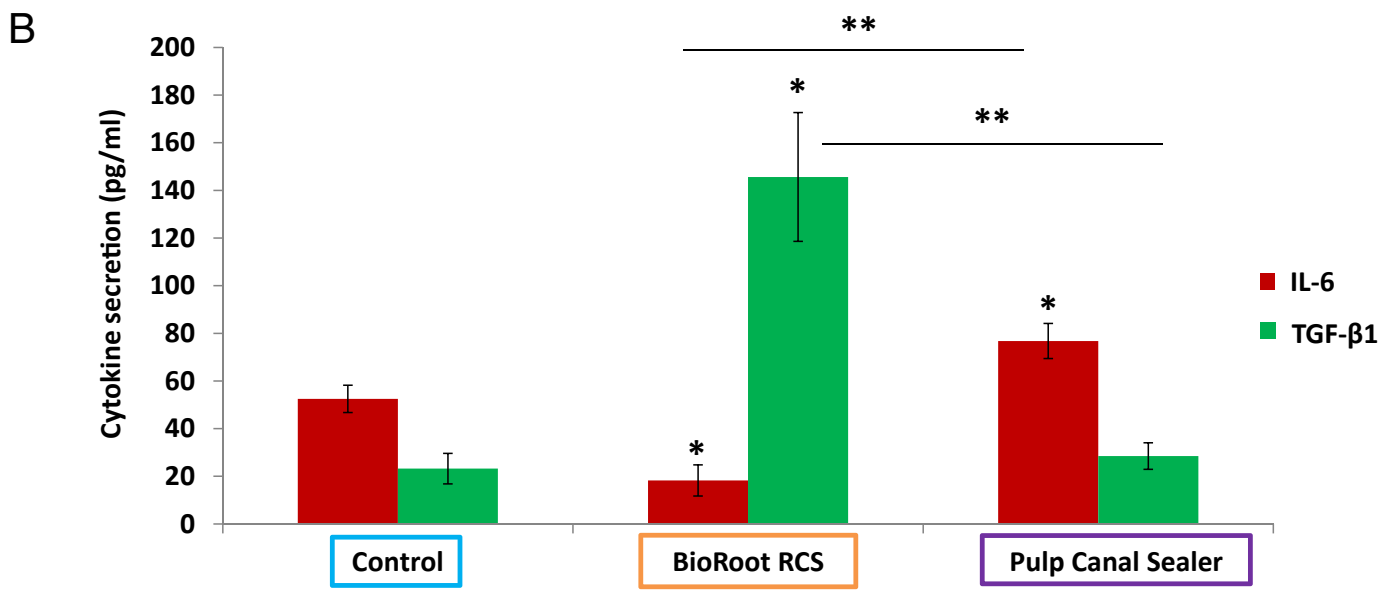

FIGURE 1 - TGF- $\beta 1$ and IL-6 secretion by PDL fibroblasts after LPS stimulation and incubation with materials' extracts. ( $A$ ) Representative immunostaining pictures of $(a-d)$ TGF- $\beta 1$ (green) and $(e-h)$ IL-6 (red) expression under ( $a$ and $e)$ control, $(b$ and $f$ ) BRCS, $(c$ and $g)$ PCS conditions, and $(d$ and $h$ ) isotype controls. (b) A strong expression of TGF- $\beta 1$ and $(f)$ a weak labeling of IL-6 were observed with BRCS. Scale bars $=50 \mu \mathrm{m}$. $(B)$ Enzyme-linked immunosorbent assay quantification of the secretion in $\mathrm{pg} / \mathrm{mL}$ after incubation for 24 hours with the materials' extracts. BRCS significantly increased TGF- $\beta 1$ secretion and inhibited IL-6 secretion compared with the control and PCS. PCS had no effect on TGF- $\beta 1$ secretion and significantly increased IL-6 secretion compared with the control and BRCS. ${ }^{*}$ A statistical difference with the control condition. ${ }^{* \star} A$ statistical difference between the 2 materials. 
carboxyethyl)-5-(and-6)-carboxyfluorescein acid for 1 hour. These $2^{\prime}, 7^{\prime}$-bis-(2carboxyethyl)-5-(and-6)-carboxyfluorescein acid-labeled THP- 1 cells $(25,000$ cells $/ \mathrm{mL})$ were added to the HUVEC monolayers (30 minutes, $4^{\circ} \mathrm{C}$ ) under gentle orbital rotation as described previously ${ }^{19}$. HUVEC monolayers were washed 4 times with PBS, and labeled THP-1-adherent cells were counted in 5 random fields using a fluorescent microscope. The results are expressed as a percentage of the control.

\section{Inflammatory THP-1 Cell Migration}

Migration was studied using Boyden chambers (8- $\mu \mathrm{m}$ pore size) in 12-well plates. Confluent PDL fibroblasts were cultured in the lower chambers. They were stimulated with LPS (4 hours, $1 \mu \mathrm{g} / \mathrm{mL}$ ) and then incubated with $1 \mathrm{~mL}$ material extract or serum-free MEM (control) $\left(24\right.$ hours, $\left.37^{\circ} \mathrm{C}\right)$. THP-1 cells were activated with phorbol myristate acetate (400 ng/mL, 24 hours) and seeded $(15,000$ cells $/ 100 \mu L)$ in the upper chambers.
After 24 hours of migration, THP-1 cells on the top side of the upper chamber were eliminated using a cotton bud, and cells on the lower surface of the upper chamber were fixed (cold ethanol 70\%, 15 minutes) and stained (eosin, 20 minutes). The number of migrating cells was counted in 5 random fields using light microscopy. The results are expressed as a percentage of the control (cells migrating in response to LPS-stimulated PDL fibroblasts incubated in MEM).

\section{Inflammatory THP-1 Cell Activation}

THP-1 suspension (25,000 cells/mL) was cultured with PDL conditioned medium in 12-well plates ( 24 hours, $37^{\circ} \mathrm{C}$ ). Then, the wells were washed 4 times with PBS to remove nonactivated and dead cells. Adherent cells were fixed (cold ethanol 70\%, 15 minutes) and nuclei stained with DAPI $(1 \mu \mathrm{g} / \mathrm{mL})$. The number of activated (adherent) cells was counted in 5 random fields using a fluorescent microscope. The results are expressed as a percentage of the control.

\section{PDL Fibroblast Proliferation}

PDL fibroblasts were cultured at a low density (1000 cells $/ \mathrm{cm}^{2}$ ) in 12-well plates for 24 hours and then stimulated with LPS $(1 \mu \mathrm{g} / \mathrm{mL}$, 4 hours). Next, media were replaced by material extracts or serum-free MEM control media. After 3, 6, and 9 days, the supernatants were removed, and a MTT assay was performed as described previously ${ }^{15}$ to measure cell proliferation ${ }^{20,21}$. The results are expressed as a percentage of the control on day 3 , which was considered the baseline.

\section{PDL Stem Cell Migration}

Migration assays were performed using Boyden chambers (12-well plates fitted with $8-\mu \mathrm{m}$ pore Boyden inserts). PDL fibroblasts were cultured in the lower chamber at confluence. After their stimulation (LPS, $1 \mu \mathrm{g}$ / $\mathrm{mL}, 4$ hours), they were incubated in serumfree MEM (control) or in material extracts (1 $\mathrm{mL}$ ). The upper chambers (inserts) were seeded with PDL stem cells ( $10^{4}$ cells $\left./ 100 \mu \mathrm{L}\right)$.
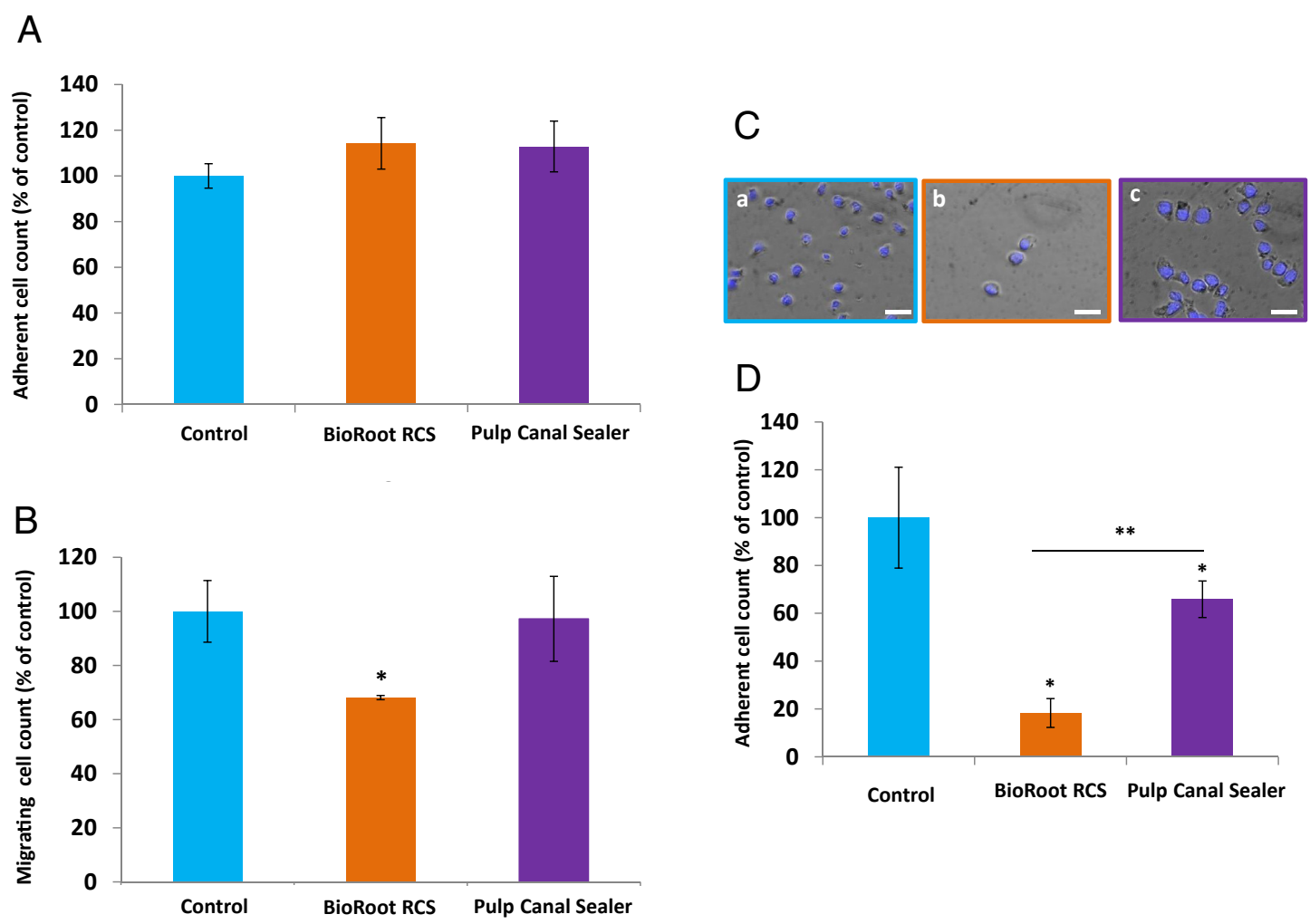

FIGURE 2 - Inflammatory cell recruitment sequence modulation by the materials' extracts. ( $A$ ) Inflammatory cell (THP-1) adhesion on the endothelial cell (HUVEC) monolayer using conditioned media from both materials' extracts or MEM media (control). No significant differences were observed between all conditions. (B) THP-1 cell migration in Boyden chambers toward LPS-stimulated PDL fibroblasts incubated with materials' extracts. BRCS significantly decreased THP-1 cell migration compared with the control and PCS conditions. (C) THP-1 cell activation using conditioned media from both materials' extracts. Representative pictures used for cell count from the (a) control, (b) BRCS, and (c) PCS. Scale bars $=50 \mu \mathrm{m}$. BRCS and PCS significantly decreased inflammatory cell activation compared with the control. (D) The reduction with BRCS was also significant compared with PCS. The results are expressed as a percentage of the control. *A statistical difference with the control condition. ${ }^{* *} A$ statistical difference between the 2 materials. 
After 24 hours, migrating cells on the lower side of the membrane were fixed (cold ethanol $70 \%, 15$ minutes) and then stained (hematoxylin, 20 minutes). Migrating cells were counted in 5 random fields using light microscopy. The results are expressed as a percentage of the control (cells migrating in response to LPS-stimulated PDL fibroblasts incubated in MEM).

\section{Statistical Analysis}

All experiments were performed in triplicate and repeated 3 times. Data are expressed as means \pm standard error of the mean. The Student $t$ test was used to determine statistical significance $(P<.05)$.

\section{RESULTS}

\section{BRCS Induced TGF- $\beta 1$ and Inhibited IL-6 Secretion by PDL Fibroblasts}

After LPS stimulation of PDL fibroblasts and incubation with MEM (control) or with BRCS or PCS extracts, immunofluorescence showed that PDL fibroblasts expressed TGF- $\beta 1$ (Fig. $1 A a-d$ ) and IL-6 (Fig. 1Ae-h). An intense TGF- $\beta 1$ labeling was observed with BRCS extract (Fig. 1Ab), whereas that of IL-6 was weakly stained (Fig. 1Af) compared with the control (Fig. 1Aa and e) and PCS (Fig. 1AC and g). No expression was observed with isotype controls (Fig. $1 A d$ and $h$ ). An enzyme-linked immunosorbent assay showed that BRCS significantly induced TGF- $\beta 1$ secretion and significantly reduced IL-6 secretion compared with the control and PCS. On the contrary,
PCS induced IL-6 secretion compared with the control (Fig. 1B).

\section{BRCS Modulated Inflammatory Cell Recruitment Sequence}

The use of conditioned media from both materials did not affect THP-1 cell adhesion onto the HUVEC monolayer compared with the control (Fig. 2A). THP-1 migration toward LPS-stimulated PDL fibroblasts was significantly reduced with BRCS compared with the control and PCS (Fig. 2B). Finally, as illustrated with representative pictures (Fig. 2Ca-C), BRCS and PCS conditioned media significantly reduced THP-1 activation compared with the control. However, this decrease was significantly more important with BRCS compared with PCS (Fig. $2 C$ and D).

\section{BRCS Induced PDL Fibroblast Proliferation}

Pictures of an LPS-stimulated PDL fibroblast MTT assay show an increased staining after incubation with BRCS (Fig. $3 A a-C$ ) and a decrease with PCS (Fig. 3Ad-f). Quantitative analysis of the results shows a significant increase of PDL fibroblast proliferation after 6 and 9 days with BRCS extracts compared with the control. By contrast, this proliferation significantly decreased after 6 and 9 days with PCS compared with the control (Fig. 3B).

\section{PCS Decreased PDL Stem Cell Migration}

The STRO-1-sorted PDL cells proliferated forming colony-forming units, a characteristic of stem cells (Fig. $4 A a-C$ ). Cell characterization was performed by immunofluorescence with 6 characteristic stem cell markers (STRO-1, CD44, CD90, CD105, CD106, and CD166), 1 hematopoietic cell marker (CD45), and 1 leukocyte marker (CD19). The results showed that sorted cells expressed STRO-1 (Fig. 4Ad), CD90 (Fig. 4Ae), CD105 (Fig. 4Af), CD44 (Fig. 4Ag), CD106 (Fig. 4Ah), and CD166 (Fig. 4Ai). On the contrary, they did not express CD45 or CD19 (Fig. $4 A j$ and $k$ ). Isotype controls were negative (Fig. 4Al). Reverse transcription polymerase chain reaction confirmed the stem cell nature of the sorted PDL cells because characteristic transcription factor genes KLF4, NANOG, OCT3/4, and SOX2 were expressed (Fig. $4 A m$ ). Investigation of the characterized PDL stem cell migration showed that this migration was not affected by BRCS but was significantly reduced by PCS compared with the control (Fig. 4B).

\section{DISCUSSION}

This study shows that applying endodontic sealers' extracts on LPS-stimulated PDL fibroblasts modulates the early mechanisms of inflammation and regeneration after infected/ necrotic tissue removal. The modulatory effect of inflammation was studied by investigating proinflammatory IL-6 cytokine secretion and the consequences of adding the materials' extracts on the initial mechanisms involved in the inflammation, which include adhesion of inflammatory cells onto the vascular endothelium, their migration to the stimulation site, and their activation. The effect on

\section{A}

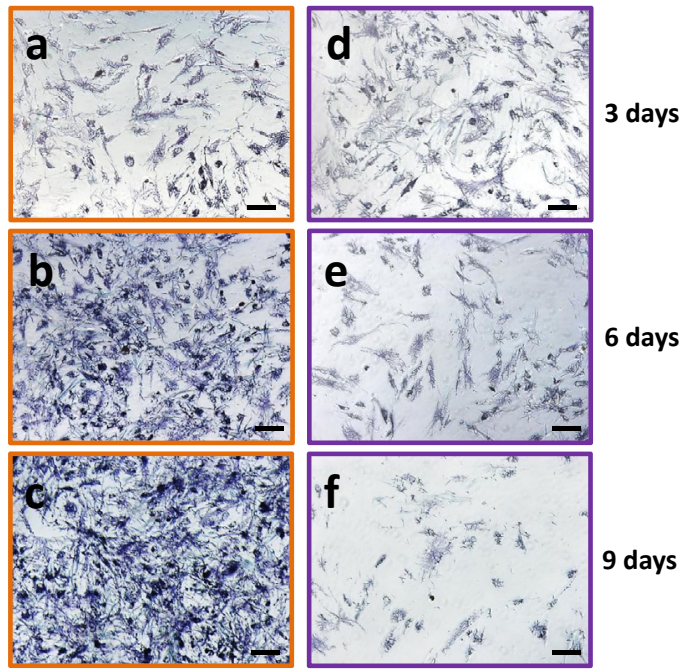

B

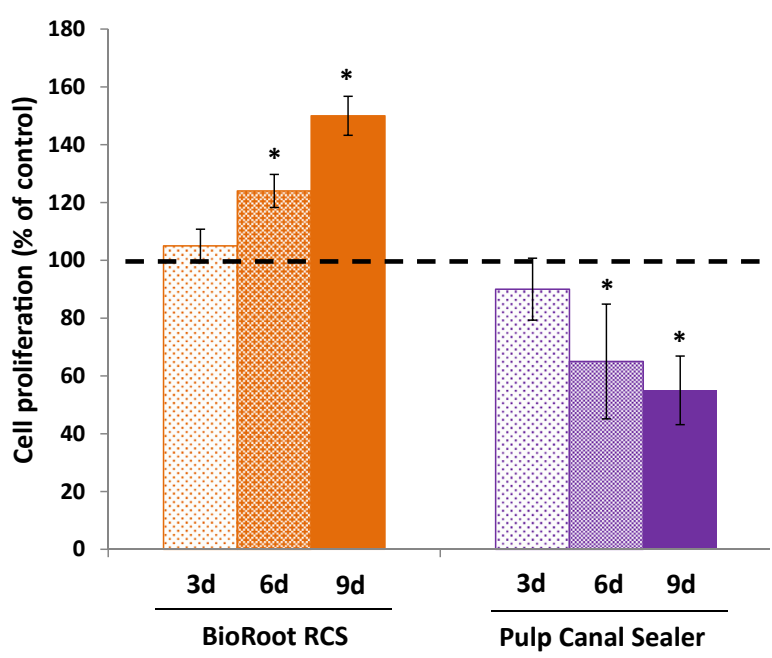

FIGURE 3 - Materials' effects on PDL fibroblast proliferation. ( $A$ ) Representative pictures of fibroblasts with the MTT assay after 3,6 , and 9 days using (a-C) BRCS or ( $d-f)$ PCS extracts. Scale bars $=50 \mu \mathrm{m} .(B)$ Quantitative analysis showed a significant increase of proliferative cells with BRCS after 6 and 9 days, whereas a significant decrease was observed with PCS. The results are expressed as a percentage of the control (3 days, baseline). ${ }^{*} A$ statistical difference with the control condition. 
A

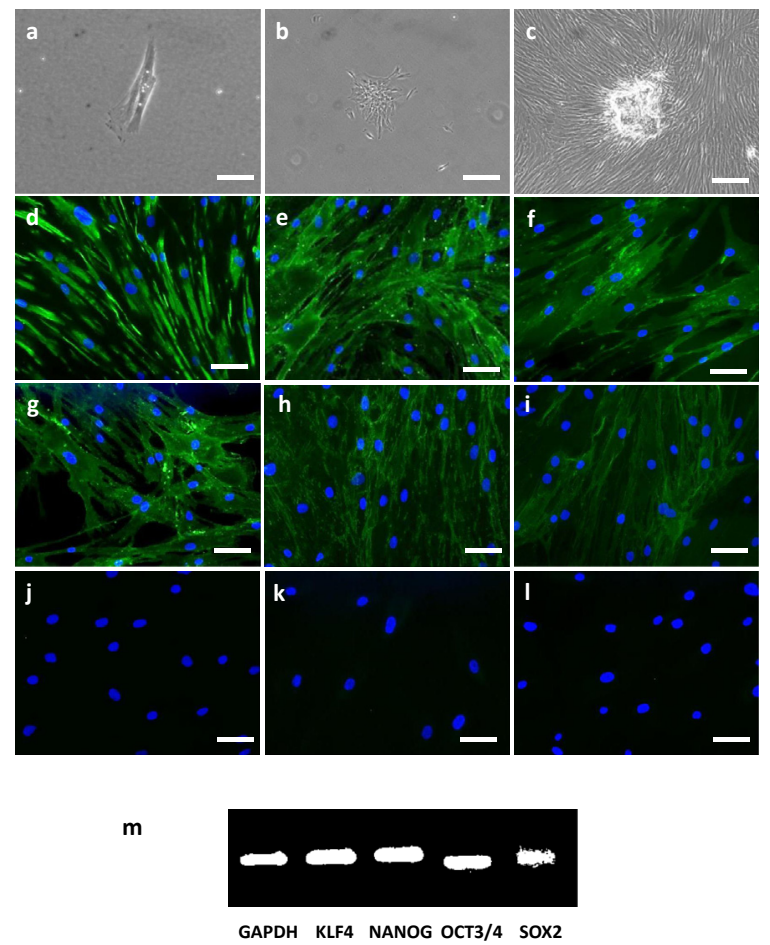

B

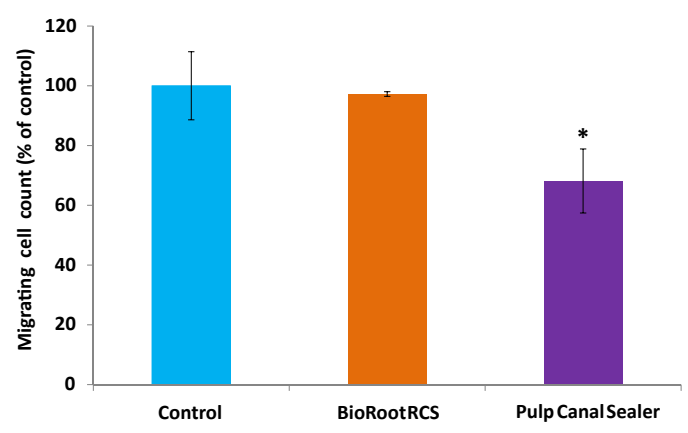

FIGURE 4 - PDL stem cell characterization and the effect of sealers on their migration. ( $A$ ) Pictures showing $(a-c)$ PDL STR0-1-positive colony-forming units. Immunofluorescence expression of $(d)$ STR0-1, (e) CD90, ( $f$ ) CD105, ( $g$ ) CD44, ( h ) CD106, (i) CD166, (j) CD45, (k) CD19, and ( $)$ isotype control. Scale bars = $50 \mu \mathrm{m}$ for a; $500 \mu \mathrm{m}$ for $b$ and $c$; and 100 $\mu \mathrm{m}$ for $d-l$. $(m)$ Reverse transcription polymerase chain reaction of KLF4, NANOG, OCT3/4, and SOX2 on STRO-1 isolated PDL stem cells. (B) The effect of sealers on PDL stem cell migration in Boyden chambers toward LPS-stimulated PDL fibroblasts. PCS extracts significantly decreased stem cell migration. No effect on this migration was observed with BRCS. Results are expressed as a percentage of the control. *A statistical difference with the control condition.

modulating the early steps of regeneration was investigated through TGF- $\beta 1$ secretion and the consequences of adding the sealers' extracts on PDL fibroblast proliferation and migration of PDL stem cells to the stimulation site.

The previously mentioned inflammatory events have been shown to play a significant role in periodontitis and bone resorption ${ }^{22}$. On the other hand, after endodontic treatment, periapical healing/regeneration is dependent not only on adequate root canal treatment procedure but also on several parameters that have a pivotal role in the successful outcome including the material choice ${ }^{23}$. This suggests that, in addition to its function as a sealer, the modulation of the early mechanisms of inflammation and regeneration by the sealer could improve the endodontic treatment outcome.

In this experimental design, LPSstimulated PDL fibroblasts were used as the inflammatory response of the periodontal tissue results from root canal bacterial infection. Gram-negative bacteria involvement in root canal infection has been well shown ${ }^{24}$. In addition, the presence of LPS, a gram-negative bacterial component ${ }^{25}$, was correlated to endodontic symptoms in necrotic teeth ${ }^{26}$, and its stimulation of periapical tissue inflammation and destruction have been shown ${ }^{27}$. The rationale in choosing interactions between material extracts and LPS-stimulated PDL cells is that, after root canal filling, the filling material may exceed the apex and interact with the periapical tissues including the PDL and/or the alveolar bone. The success of endodontic treatment depends not only on the sealer's mechanical sealing function in preventing recurrent infection of the periapical space ${ }^{28}$ but also on the sealer's capacity to arrest the inflammation and induce apical hard tissue formation. PDL is known to have a population of mesenchymal stem cells, and these cells are responsible for hard tissue formation during the regeneration process ${ }^{29}$. This explains why we isolated and characterized PDL stem cells and investigated their migration toward LPSstimulated fibroblasts to check the effect of the presence of sealers on their migration and subsequent hard tissue formation. Incubating PDL fibroblasts with PCS appeared to modulate these events. Indeed, PCS extracts significantly increased proinflammatory IL-6 secretion from PDL fibroblasts and inhibited PDL stem cell migration and PDL fibroblast proliferation.
These results are in line with the previously reported toxicity of PCS in vitro ${ }^{12,30}$. This increased proinflammatory activity may appear surprising because PCS is a ZOE, and these sealers are widely used for their reported antiinflammatory effects because of eugenol; yet, eugenol effects on dental tissues are controversial ${ }^{31}$. Indeed, a localized inflammation with ZOE sealers has been observed, both in soft and bone tissue ${ }^{32}$. Additionally, in vivo studies with ZOE intentional overfilling in monkeys over a 6-month period ${ }^{33}$ showed a severe irritation over the full 6-month duration.

By contrast, BRCS decreased IL-6 proinflammatory cytokine secretion and inflammatory cell recruitment, whereas it increased TGF- $\beta 1$ secretion and induced PDL fibroblast proliferation. IL-6 is considered as a potent cytokine playing a major role in the acute inflammation process ${ }^{34}$. Its decrease, together with the subsequent decreased inflammatory cell migration/activation, suggests a BRCS anti-inflammatory potential. This result is in line with previously reported data with another tricalcium silicate-based material ${ }^{3}$.

On the other hand, while investigating the early mechanisms of regeneration, our 
work showed an increase of TGF- $\beta 1$ secretion. This is in line with a previous investigation that showed that a similar tricalcium silicate-based material, Biodentine (Septodont), induced TGF- $\beta 1$ secretion from pulp cells ${ }^{35}$. Although TGF- $\beta 1$ has been shown to exert pro- or antiinflammatory effects depending on the applied concentrations and target tissue, our previous investigations have shown that after encapsulation of this factor in polylactic/ polyglycolic acid microspheres, its sustained release guided pulp stem cell recruitment ${ }^{15,35}$ and induced the initial steps of regeneration ${ }^{35}$. The increase in TGF- $\beta 1$ secretion is also in agreement with a previously reported work showing that BRCS induced a significant increase in vascular endothelial growth factor, fibroblast growth factor 2 , and bone morphogenetic protein 2 from PDL cells ${ }^{12}$. This growth factor has been shown to play a significant role in mesenchymal stem cell recruitment ${ }^{15}$ and osteoblastic differentiation ${ }^{16}$.

Overall, this work reports that the early steps of inflammation/regeneration and their modulation by root canal sealers can be investigated in vitro. The anti-inflammatory potential reported with BRCS requires further investigations to be confirmed in vivo.

Nevertheless, this work highlights the fact that, in addition to an adequate root canal treatment procedure, the sealers' properties should be considered to improve the clinical outcome of endodontic treatment.

\section{ACKNOWLEDGMENTS}

The authors thank Dr Jean-Charles Gardon for providing the teeth.

Supported by Aix-Marseille University and Centre National de la Recherche Scientifique.

The authors deny any conflicts of interest related to this study.

\section{REFERENCES}

1. Bernáth M, Szabó J. Tissue reaction initiated by different sealers. Int Endod J 2003;36:256-61.

2. Lin LM, Rosenberg PA. Repair and regeneration in endodontics. Int Endod J 2011;44:889-906.

3. Giraud T, Jeanneau C, Bergmann M, et al. Tricalcium silicate capping materials modulate pulp healing and inflammatory activity in vitro. J Endod 2018;44:1686-91.

4. Jagtap P, Shetty R, Agarwalla A, et al. Comparative evaluation of cytotoxicity of root canal sealers on cultured human periodontal fibroblasts: in vitro study. J Contemp Dent Pract 2018;19:84752.

5. Kaur M, Singh H, Dhillon JS, et al. MTA versus Biodentine: review of literature with a comparative analysis. J Clin Diagn Res 2017;11:ZG01-5.

6. Siboni F, Taddei P, Zamparini F, et al. Properties of BioRoot RCS, a tricalcium silicate endodontic sealer modified with povidone and polycarboxylate. Int Endod J 2017;50(Suppl 2):e120-36.

7. Arias-Moliz MT, Camilleri J. The effect of the final irrigant on the antimicrobial activity of root canal sealers. J Dent 2016;52:30-6.

8. Jung S, Libricht V, Sielker S, et al. Evaluation of the biocompatibility of root canal sealers on human periodontal ligament cells ex vivo. Odontology 2019;107:54-63.

9. Collado-González M, García-Bernal D, Oñate-Sánchez RE, et al. Biocompatibility of three new calcium silicate-based endodontic sealers on human periodontal ligament stem cells. Int Endod 2017;50:875-84.

10. Dimitrova-Nakov $\mathrm{S}$, Uzunoglu E, Ardila-Osorio H, et al. In vitro bioactivity of Bioroot ${ }^{\mathrm{TM}} \mathrm{RCS}$, via A4 mouse pulpal stem cells. Dent Mater 2015;31:1290-7.

11. Loison-Robert LS, Tassin M, Bonte E, et al. In vitro effects of two silicate-based materials, Biodentine and BioRoot RCS, on dental pulp stem cells in models of reactionary and reparative dentinogenesis. PLoS One 2018;13:e0190014.

12. Camps J, Jeanneau C, El Ayachi I, et al. Bioactivity of a calcium silicate-based endodontic cement (BioRoot RCS): interactions with human periodontal ligament cells in vitro. J Endod 2015;41:1469-73.

13. Svensson D, Aidoukovitch A, Anders E, et al. Secretory leukocyte protease inhibitor regulates human periodontal ligament cell production of pro-inflammatory cytokines. Inflamm Res 2017;66:823-31.

14. Yun I-G, Ahn S-H, Yoon W-J, et al. Litsea japonica leaf extract suppresses proinflammatory cytokine production in periodontal ligament fibroblasts stimulated with oral pathogenic bacteria or interleukin-1 $\beta$. Int J Mol Sci 2018;19:E2494.

15. Mathieu S, Jeanneau C, Sheibat-Othman N, et al. Usefulness of controlled release of growth factors in investigating the early events of dentin-pulp regeneration. J Endod 2013;39:228-35.

16. Li R, Zhang Q. HtrA1 may regulate the osteogenic differentiation of human periodontal ligament cells by TGF- $\beta 1$. J Mol Histol 2015;46:137-44. 
17. Rombouts C, Jeanneau C, Camilleri J, et al. Characterization and angiogenic potential of xenogeneic bone grafting materials: role of periodontal ligament cells. Dent Mater J 2016;35:900-7.

18. Chmilewsky F, Jeanneau C, Laurent $P$, et al. Pulp progenitor cell recruitment is selectively guided by a C5a gradient. J Dent Res 2013;92:532-9.

19. Mannori G, Crottet P, Cecconi O, et al. Differential colon cancer cell adhesion to E-, P-, and L-selectin: role of mucin-type glycoproteins. Cancer Res 1995;55:4425-31.

20. Jia M, Shi Z, Yan X, et al. Insulin and heparin-binding epidermal growth factor-like growth factor synergistically promote astrocyte survival and proliferation in serum-free medium. J Neurosci Methods 2018;307:240-7.

21. Kara C, Selamet H, Gökmenoğlu C, et al. Low level laser therapy induces increased viability and proliferation in isolated cancer cells. Cell Prolif 2018;51:e12417.

22. Martinho FC, Chiesa WM, Leite FR, et al. Correlation between clinical/radiographic features and inflammatory cytokine networks produced by macrophages stimulated with endodontic content. J Endod 2012;38:740-5.

23. Holland R, Gomes JE, Cintra LT, et al. Factors affecting the periapical healing process of endodontically treated teeth. J Appl Oral Sci 2017;25:465-76.

24. Narayanan LL, Vaishnavi C. Endodontic microbiology. J Conserv Dent 2010;13:233-9.

25. Lüderitz O, Tanamoto K, Galanos C, et al. Lipopolysaccharides: structural principles and biologic activities. Rev Infect Dis 1984;6:428-31.

26. Jacinto RC, Gomes BP, Shah HN, et al. Quantification of endotoxins in necrotic root canals from symptomatic and asymptomatic teeth. J Med Microbiol 2005;54:777-83.

27. Hong C-Y, Lin S-K, Kok S-H, et al. The role of lipopolysaccharide in infectious bone resorption of periapical lesion. J Oral Pathol Med 2004;33:162-9.

28. Grossman L. Endodontic Practice. 10th ed. Philadelphia: Lea \& Febiger; 1981. p. 27-9.

29. Huang GT, Gronthos S, Shi S. Mesenchymal stem cells derived from dental tissues vs. those from other sources. J Dent Res 2009;88:792-806.

30. Lee J-H, Lee H-H, Kim K-N, et al. Cytotoxicity and anti-inflammatory effects of zinc ions and eugenol during setting of ZOE in immortalized human oral keratinocytes grown as threedimensional spheroids. Dent Mater 2016;32:e93-104.

31. Hauman $\mathrm{CH}$, Love RM. Biocompatibility of dental materials used in contemporary endodontic therapy: a review. Part 2. Root-canal-filling materials. Int Endod J 2003;36:147-60.

32. Yesilsoy C, Koren LZ, Morse DR, et al. A comparative tissue toxicity evaluation of established and newer root canal sealers. Oral Surg Oral Med Oral Pathol 1988;65:459-67.

33. Hong YC, Wang JT, Hong CY, et al. The periapical tissue reactions to a calcium phosphate cement in the teeth of monkeys. J Biomed Mater Res 1991;25:485-98.

34. Heinrich PC, Castell JV, Andus T. Interleukin-6 and the acute phase response. Biochem J 1990;265:621-36.

35. Laurent P, Camps J, About I. Biodentine(TM) induces TGF- $\beta 1$ release from human pulp cells and early dental pulp mineralization. Int Endod J 2012;45:439-48. 